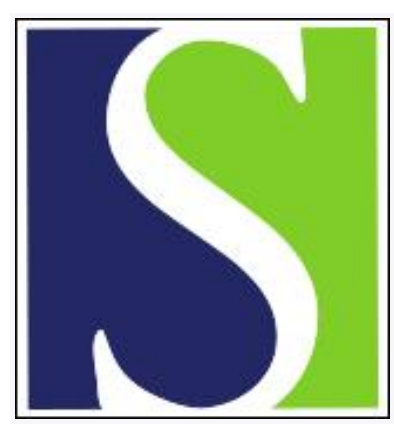

Scand J Work Environ Health 2000;26(5):369-371

https://doi.org/10.5271/sjweh.556

Issue date: Oct 2000

\title{
Occupation and lung disease
}

by Burge $S$

This article in PubMed: www.ncbi.nlm.nih.gov/pubmed/11103834

\section{(c) (i)}




\section{Occupation and lung disease}

Diseases have causes and consequences. The precise etiologic causes of lung diseases have received more attention than those of many other illnesses, partly because the response of the lungs to external agents can be monitored (with lung function tests) with more precision than that of many other organs and partly because most lung diseases can be initiated by substances inhaled and these substances can be measured in the air we breathe. There are huge variations in the incidence of lung diseases around the world. For instance, asthma is more than 40 times as common in some countries as in others, and it has increased by more than $200 \%$ in our lifetime $(1,2)$. Similar variations occur for lung cancer, chronic obstructive pulmonary disease (COPD), tuberculosis, and pneumonia. All of these diseases can be caused by exposures at work.

The chest $X$ ray was the first objective method for assessing the lungs, and it formed the basis for compensation for occupational lung diseases. Dust retention in the lung, and the inflammatory and fibrotic reaction to it, is often visible in chest radiographs, and pneumoconioses were the first wellestablished occupational lung diseases. Control measures have led to a significant reduction in pneumoconioses, at least in developed countries (3). The chest $X$ ray, however, can lead to much confusion in that, although the visible changes relate to cumulative exposure, they relate poorly to disability. As a "disease" was defined in terms of $X$-ray changes, it was assumed that persons with similar exposures and normal $X$ rays had no disease. Recent work, for instance, with silica and coal dust exposure, has shown that the main disability relates to airflow obstruction, which is related to cumulative exposure. The degree of impairment in the forced expiratory volume in 1 second $\left(F E V_{1.0}\right)$, for example, is not related to the presence or absence of $X$-ray changes of simple pneumoconiosis (4).

The availability of spirometers measuring $\mathrm{FEV}_{1.0}$, and portable peak expiratory flow meters, has revolutionized the investigation of asthma and the documentation of provoking factors $(5,6)$. Occupational asthma was regarded as a rare disease before measurements of airflow obstruction were widely available; it is now the most commonly recognized occupational lung disease in many countries (3). Work-related decreases in peak expiratory flow can be used to document the provocation of asthma by an occupational exposure in that such changes can be seen in the absence of the traditional features of asthma, such as specific immunoglobulin $E$ (IgE), increased nonspecific reactivity, and eosinophilia in induced sputum. Whether the workers involved have occupational asthma or another as yet unnamed airway disease, is currently unclear, as is the consequences with continued exposure.

The diseases discussed so far all have features that distinguish occupational from nonoccupational causes. Occupational exposures can also lead to COPD and lung cancer, both of which can be caused by occupational and nonoccupational factors that produce indistinguishable disease that can only be attributed to a particular cause using epidemiologically derived estimates of risk. Epidemiologic studies of chronic disease in the workplace is notoriously difficult, as workers who develop a chronic disease generally leave employment and only those who are relatively resistant to the effects of the occupational exposure remain to be studied. Research sometimes shows that workers with the highest exposures have the highest lung function. This situation is compounded by the healthy worker effect in that those who are at work are selected for their above-average health. Studies show that those entering the dustiest jobs may have even had higher lung function at the time of employment than those entering less risky employment. These factors result in younger workers with exposures likely to cause occupational COPD being healthier than their referents and those with the most severe disease having been removed 
from the cohort, leaving a survivor population (7). To overcome these problems several groups have studied community-based cohorts, usually utilizing measurements made during a survey (7-9).

In this issue of the Scandinavian Journal of Work, Environment \& Health Nathel and his colleagues (10), for the first time ( $p 380$ ), use nationally collected sickness absence statistics in Sweden as an outcome and relate this information to occupational group. The data only include sickness absence for 14 or more days and therefore are likely to exclude most of those with occupational asthma. The paper shows an association between long-term respiratory sickness, and sickness from all causes, that could be due to the less fit taking particular jobs, such as caretaking. Agricultural and industrial workers had a higher proportion of long-term respiratory sickness when they were compared with other groups, hotel and restaurant workers having the lowest proportion. Whereas studies based on community surveys have shown a higher prevalence of COPD among farmers (7-9), the Swedish study finds a lower-thanaverage incidence of long-term respiratory illness among construction workers, a group with increased COPD risks in other survey-based studies $(7,8)$. It would be important to know whether this finding was due to local differences in exposure (such as iron in the cement) or to technical factors relating to the study methodology. Studies of sickness absence depend on the acceptability of sickness absence, which may vary from industry to industry. In some countries construction workers would be more likely to lose their jobs if they had to take a 2-week sick leave than, for instance, a farmer. Therefore the more prolonged sickness absences of construction workers are generally for more serious diseases than respiratory infections. Whether the same situation applies in Sweden is unclear.

The challenge is to convert this type of epidemiologic data into information specific enough to initiate changes in work practice. At present the main strength of community-based studies is their inclusion of all those living, whether fit or unfit for work; their weakness is the occupational groupings employed, which combine many people with dissimilar exposures. Agricultural workers include several groups with known increased risks of occupational COPD, such as swine confinement workers and those handling grain. It would also include those herding animals outdoors and growing fruit, whose exposures probably carry a much lower risk of COPD. The action required to prevent disease usually needs to be specific to a particular type of exposure. Community studies should be followed by studies with specific hypotheses to obtain such information. The European Community Respiratory Health Survey (predominately looking for asthma) found cleaners to have an increased risk for asthma (11). If this increased risk is due to their work, the large numbers working as cleaners would make cleaning the most prevalent cause of occupational asthma, even though the relative risk is less than, for instance, for painters Studies are now in progress that are looking at different types of cleaners (domestic, industrial, commercial, etc) and identifying particular exposures. Studies of individual workers have shown that some biocides and additives have caused occupational asthma both in cleaners and in those whose workplaces have been cleaned when they were absent $(12,13)$.

\section{References}

1. The International Study of Asthma and Allergies in Childhood (ISAAC) Steering Committee. Worldwide variation in prevalence of symptoms of asthma, allergic rhinoconjunctivitis, and atopic eczema: ISAAC. Lancet 1998;351:1225-32.

2. Sunyer J, Anto JM, Tobias A, Burney P. Generational increase of self-reported first attack of asthma in fifteen industrialized countries: European Community Respiratory Health Study (ECRHS). Eur Respir J 1999;14:885-91.

3. Ross DJ. Ten years of the SWORD project (Surveillance of Work-related and Occupational Respiratory Disease). Clin Exp Allergy 1999;29:750-3.

4. Oxman AD, Muir DC, Shannon HS, Stock SR, Hnizdo E, Lange HJ. Occupational dust exposure and chronic obstructive pulmonary disease: a systematic overview of the evidence. Am Rev Respir Dis 1993;148:38-48.

5. Gannon PF, Newton DT, Belcher J, Pantin CF, Burge PS. Development of OASYS-2: a system for the analysis of serial measurement of peak expiratory flow in workers with suspected occupational asthma. Thorax 1996;51:484-9.

6. Burge PS, Pantin CFA, Newton DT, Gannon PFG, Bright P, Belcher J, et al. Development of an expert system for the interpretation of serial peak expiratory flow measurements in the diagnosis of occupational asthma. Occup Environ Med $1999 ; 56: 758-64$ 
7. Krzyzanowski M, Kauffmann F. The relation of respiratory symptoms and ventilatory function to moderate occupational exposure in a general population: results from the French PAARC study of 16,000 adults. Int J Epidemiol 1988;17:397_ 406.

8. Heederik D, Pouwels H, Kromhout H, Kromhout D. Chronic non-specific lung disease and occupational exposures estimated by means of a job exposure matrix: the Zutphen Study. Int J Epidemiol 1989;18:382—9.

9. Humerfelt S, Gulsvik A, Skjaerven R, Nilssen S, Kvale G, Sulheim O, et al. Decline in FEV1 and airflow limitation related to occupational exposures in men in an urban community. Eur Respir J 1993;6:1095-103.

10.Nathell L, Malmberg P, Lundbäck B, Nygren $\AA$. Impact of occupation on respiratory disease. Scand J Work Environ Health 26(5):380-7.

11.Kogevınas M, Anto JM, Sunyer J, Tobias A, Kromhout H, Burney P (European Community Respiratory Health Survey Study Group). Occupational asthma in Europe and other industrialised areas: a population-based study. Lancet 1999;353:1750-4.

12.Burge PS, Richardson MN. Occupational asthma due to indirect exposure to lauryl dimethyl benzyl ammonium chloride used in a floor cleaner. Thorax 1994;49:842-3.

13.McCoach J, Robertson AS, Burge PS. Floor cleaning materials as a cause of occupational asthma. In: Raw G, Aizlewood C, Warren P, editors. Building Research Establishment; Watford. 1999;5:459-65. Indoor Air 99.

\section{Sherwood Burge \\ Occupational Lung Disease Unit \\ Birmingham Heartlands Hospital \\ Bordesley Green East \\ Birmingham B9 5SS, United Kingdom}

